BMJ Paediatrics Open

\section{Delivery of the UN Convention on the Rights of the Child in an acute paediatric setting: an audit of information available and service gap analysis}

To cite: Przybylska MA, Burke N, Harris C, et al. Delivery of the UN Convention on the Rights of the Child in an acute paediatric setting: an audit of information available and service gap analysis. BMJ Paediatrics Open 2019;3:e000445. doi:10.1136/ bmjpo-2019-000445

- Additional material is published online only. To view please visit the journal online (http://dx.doi.org/10.1136/ bmjpo-2019-000445)

Received 17 January 2019

Revised 29 April 2019

Accepted 9 May 2019

\section{Check for updates}

C) Author(s) (or their employer(s)) 2019. Re-use permitted under CC BY-NC. No commercial re-use. See rights and permissions. Published by BMJ.

Department of General Paediatrics, Royal Hospital for Sick Children, Edinburgh, UK

Correspondence to

Dr Sonia Joseph; sonia.joseph@ nhs.net

\section{ABSTRACT}

Background The United Nations Convention on Children's Rights stresses the importance of providing children with information relating to their health and wellbeing, yet reports suggest children are offered insufficient support in healthcare environments. We audited the information provided to children and families requiring planned surgical admission in comparison to those admitted acutely to medical paediatrics. Additionally, we identified examples of child-specific information resources in national and international hospitals.

Methods Three approaches were taken to gain insight into practice locally, nationally and internationally.

(1) Information resources provided to paediatric inpatients admitted to the acute receiving unit were audited in comparison to information given to children with planned admissions via process observations.

(2) Qualitative feedback was gained from play specialists $(n=2)$, families $(n=30)$ and children $(n=9$; aged $3-15$ years) via interviews.

(3) A review, including UK, Australian and US hospitals, was conducted to assess child-specific information resources ( $\mathrm{n}=36$ hospitals) and to systematically compare the information available on websites ( $\mathrm{n}=9$ hospitals).

Results At the study site, no child-specific information resources were available for acute admissions, whereas planned admissions were offered significant information face-to-face with supplemental resources. Child, parent and play specialist interviews highlighted gaps in information provision regarding hospital practicalities and processes. Twelve external child-specific resources were identified, for 4-14 year olds, explaining key care information: medical procedures, equipment and staff. These resources could positively respond to the topics cited as lacking by the interviewed patients and families at the study site. International hospital websites provided considerably more in-depth information compared with UK hospitals.

Conclusions The hospital experience of children and families can be improved by ensuring they are provided with adequate information relating to their hospital stay. It is essential that suitable high-quality resources are consistently available and that feedback from children informs the process of resource development.

\section{INTRODUCTION}

The United Nations Convention on the Rights of the Child (CRC) was created in 1989 with the UK signing the convention in April 1990 with implementation in 1992. ${ }^{1}$ Article 17 of the convention states, "Children have the right to get information that is important to their health and well-being." Article 24 focuses on health and health services, stating, "Children have the right to good quality healthcare-the best healthcare possibleto safe drinking water, nutritious food, a clean and safe environment, and information to help them stay healthy." In 2015, the UK government published their fifth report on adherence to the CRC with subsequent publications defining strategies for review, improvement and adherence to CRC. ${ }^{2}$ The 2017 Royal College of Paediatrics and Child Health (RCPCH) paper on the 'State of Child Health' outlined aspirations for child health from a care, workforce and service delivery perspective $^{3}$ with subsequent publication of outcomes across the UK illustrating progress in work streams focusing on child poverty, obesity and mental health. ${ }^{45}$

Hospitals are a source of numerous stressors for children ${ }^{6}$ with unaddressed anxiety in hospitals associated with reduced coping ability, prolonged recovery and development of phobias with reduced patient and parental satisfaction. ${ }^{7}$ Admissions to acute paediatric units act as touch points with health services, providing an opportunity to review each child from a holistic perspective including growth parameters and social circumstances. They are a chance to listen to children and provide sufficient age-appropriate information to allow them to 
understand the healthcare environment and contribute to healthcare discussion. ${ }^{8-11}$

A 2016 survey found that 57\% of 34000 paediatric patients felt they were either not involved, or minimally involved, in making decisions about their care ${ }^{12}$ and fewer than $50 \%$ of healthcare organisations in England had a specific strategy in place to improve paediatric patient experience. ${ }^{13}$ A Scottish Children's Parliament report has highlighted the need for continued efforts to 'guide' and 'include' young people and to 'talk' to them directly, ${ }^{14}$ urging healthcare teams to consider barriers to inclusion such as age, maturity, circumstances of visit, duration of stay, potential medical procedures and capacity. Paediatric staff must balance the views of parents but there is greater recognition that paediatric service evaluations and improvements must take account of the views of children. ${ }^{15}$ The priorities of young people should be considered ${ }^{16}$ and more needs to be done to engage children in their healthcare. ${ }^{12-15}$

Efforts to empower children in healthcare settings have focused on children requiring a planned admission for surgery, ${ }^{17-29}$ as a result, preadmission programmes are widespread in the UK. In contrast, a recent study stated that $14 \%$ of paediatric patients feel that communication with staff was either not directed or only partially directed towards them ${ }^{12}$ with limited research conducted on the preparation of children admitted acutely to inpatient paediatric units. ${ }^{30}$

The national focus on CRC in 2016 and the RCPCH recommendations focused our unit to ask what resources and support are available to acutely admitted medical paediatric patients.

\section{METHODS}

The study site is a national quaternary referral centre and teaching hospital with over 58000 emergencies annually, resulting in 8500 medical paediatric admissions per year: $45 \%$ have complex care requirements, $55 \%$ discharged within 48 hours, $25 \%$ discharged within 7 days and $20 \%$ requiring prolonged admission. This variation in patient pathology, length of stay and clinical need means that focusing on the primary aim of 'sufficient age-appropriate information to allow children to understand the healthcare environment' requires an ability to provide accurate and adaptive information.

Our study had three aims. First, to audit the information currently given to children and families requiring planned surgical admissions in comparison to those admitted acutely to medical paediatric inpatients, enabling clear delineation of the 'information gap' within our institution. Second, to identify examples of child-specific information resources nationally and internationally to gain insight into the information provided, presentation styles, format and differentiation for clinical environments and age. The final aim was to triangulate detailed qualitative feedback from the experience and understanding of children admitted acutely to that of their parents and of the play specialists who routinely support the planned admission as well as the acute admission service. The hope was this whole service analysis would enable reflection and attainment of delivery of Article 17 of CRC.

\section{Resource audit}

A process map for both inpatient admission and planned admission was created. Points where information was specifically given, format, method and timing of delivery were considered. The same medical student group conducted process observations and interviews to gain an understanding of family and child experience.

\section{Patient involvement}

As no single validated questionnaire was available focusing on patient hospital resources, a quality improvement approach to questionnaire design was adopted. Three families were asked open questions about their experience and were able to add questions from their perspective. Two subsequent Plan, Do, Study, Act (PDSA) cycles of the questionnaires were trialled on a wider group of families with scoping of additional family perspectives and potential questions. A Delphi group was set up to review the questions with final revisions of the questionnaire. The fourth iteration of the questionnaire was used for the study.

\section{Process observations}

Preadmission visits (PAVs) and surgical preassessment clinics (SPACs) were observed by second year medical students $(n=6)$. PAVs are organised group activities run by play specialists which children attend a week before their scheduled hospital admission. SPACs are a one-on-one appointment with a nurse and play specialist who provide families with information regarding their upcoming hospital admission.

\section{Acute inpatient interviews}

Details of interviews (1-4) are provided in table 1.

Students had a training session with a consultant paediatrician. Patients and families were selected by convenience sampling and students had no prior contact with this group. On each study day, all families were invited to participate, the purpose of the study was explained as a review of current hospital practice and qualitative data were prospectively collected. Sample size was limited by the duration of the interview period (2weeks), and the aim was to include as many participants as possible. Interviews were conducted on the wards, lasted $30 \mathrm{~min}$, with detailed written notes taken by the interviewer and read back to families to ensure accuracy.

\section{National and international resource review}

Parent and child interviews highlighted operational information needs which parents prioritised as important for their experience and understanding of hospital inpatient environments. 
Table 1 Details of interviews

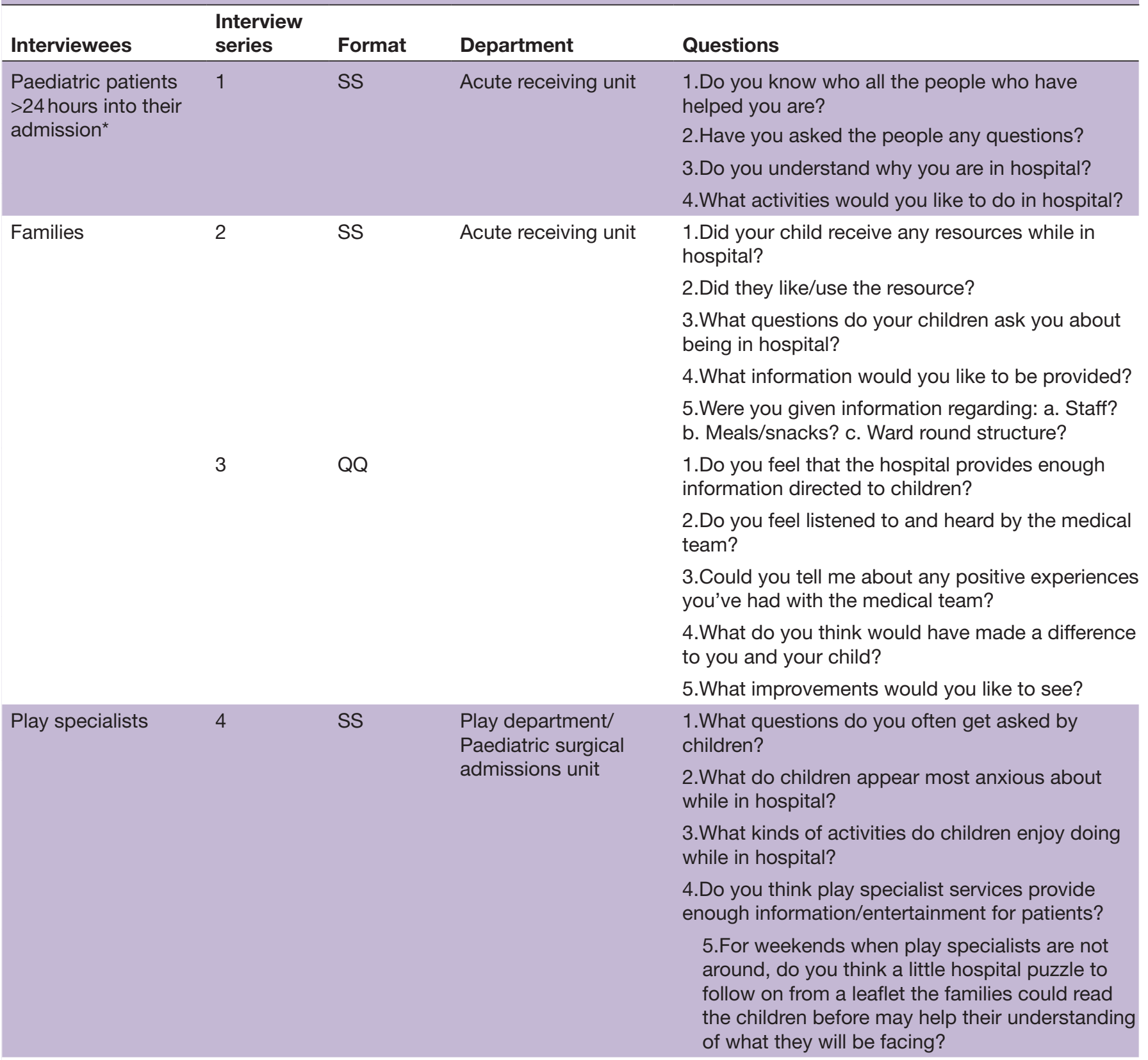

6.What additional information do you think it would be helpful to provide to children during their stay? Do you feel this information should be provided?

7.How often would children use an app/game and what age group do you think that would work for?

*Paediatric patients of any age were approached.

$Q Q$, qualitative questionnaire; SS, semistructured.

\section{Hospital websites}

These information needs were used to create a set of criteria to review external resources. The following criteria were included: location, local area, team demographics, before and after hospital visit, food, hospital amenities, children resources, child-specific information, family accommodation, family support, advice and resources, departments/services, medical conditions, treatments, procedures and feedback.

Three paediatric hospitals in Scotland and two quaternary paediatric hospitals from three English-speaking developed countries, England, Australia and USA, were chosen (online supplementary table 1). The national and international paediatric hospitals are well known among 
the public and healthcare staff, with many referencing these hospitals when seeking second opinions, patient information resources or guidelines. The intention was to carry out detailed audit of website content, hence the restriction to nine websites in total. Two students independently reviewed each hospital website according to the predefined criteria (online supplementary table 2), assigning a score (0-5) for each. Discrepancies were discussed with the consultant reviewer. An average score per category was calculated for UK and non-UK hospitals.

\section{Child-specific information resources}

While the website audit enabled a detailed review of resources from single institutions, our team wanted to carry out a broad scoping exercise for potential resources; hence, 36 hospitals were selected by convenience sampling (online supplementary table 3 ) and contacted regarding any potential child-specific resources they had available. All hospitals were emailed asking if they had child-specific resources and if they could provide access to these. Additionally, the websites of all hospitals were reviewed for content and open source resources. Students evaluated each resource against the following criteria: format, target audience, information provided and interactivity level; defined as engagement in other ways aside from reading.

\section{RESULTS}

\section{Study site resources}

Audit of PAVs and SPACs highlighted significant information and support provided to children undergoing planned admissions at our study site, including a hospital passport for procedural anxiety and preadmission booklet. Play specialist (interview series 4, $n=2$ ) believed that these resources provided enough information for children; however, one noted the PAV primarily focused on admission processes. The PAV included additional resources, such as a PowerPoint presentation, puppets, tactile demonstration of healthcare equipment (numbing cream, stethoscope) and medical toys. No child-specific resources were provided for acute paediatric inpatient admissions during the study period.

\section{Acute admission experience}

In the acute receiving unit, a total of nine paediatric patients (age range 3-15 years) admitted acutely through the emergency department were interviewed via semistructured interviews (online supplementary table 4, interview series 1), together with their parents (interview series 2). Of 22 families approached, 21 families participated in the qualitative questionnaire (interview series $3)$. Thirty eight per cent of families were on their first visit to the hospital and patient ages ranged from 3 days to 9 years, with $90 \%$ under the age of 5 .

The majority of children $(89 \%, 8 / 9)$ felt they knew who members of staff were and $78 \%(7 / 9)$ understood why they were in hospital. Among families who considered their children old enough to receive information, $89 \%(8 / 9)$ of parents felt the hospital provided enough information directed to children; however, $44 \%$ (4/9) suggested that more resources could be used to familiarise children with the hospital environment and processes. Two children noted they would like to receive more information, specifically about daily life in hospital and procedures. This was in agreement with play specialists $(n=2)$, who reported that questions about anaesthesia, medical procedures, Wi-Fi access and eating/drinking before and after surgery were commonly asked by children admitted acutely.

Parents generally regarded their admission experience as positive, with good communication with the medical team (17/21; interview series 4$)$. They reported high quality of care $(n=11)$, friendly and helpful staff $(n=15)$ and instances when they felt they were listened to, informed $(n=6)$ with support available $(n=2)$. Challenges raised included long waiting time between seeing staff $(n=2)$ and lack of parent accommodation $(n=3)$. Parents $(\mathrm{n}=7$, interview series 2$)$ would like further information on ward practicalities (eg, showers, medical rounds) and family services. Additionally, parents (interview series 3) would like information on hospital and parent-specific facilities, parking and meals prior to the hospital visit $(n=5)$. Suggested improvements included changes to the hospital website $(n=4)$ to provide more information on medical conditions, including 'red flag' symptoms and when to seek help.

\section{Review of resources}

Six out of the 36 hospitals contacted responded (17\%), with 12 child-specific resources identified from 9 different hospitals (table 2). Resources included activity books $(n=2)$, videos $(n=3)$, websites $(n=2)$, photobooks $(n=3)$, storybook $(\mathrm{n}=1)$ and a mobile device application $(\mathrm{n}=1)$. These explained staff, wards, medical procedures and equipment. Target audience ranged from 4 to 14 years old, and the interactivity level varied between resources.

The paediatric hospital website audit identified a wide range of information offered on services. International hospital provided considerably more in-depth information compared with UK hospitals (figure 1).

\section{DISCUSSION}

Our study highlighted a sparsity of operational information for paediatric acute admissions in contrast to patients with planned admissions at our institution. We identified our acutely admitted children had greater information needs as they are not prepared; although on-duty staff provided verbal information to patients and parents, non-verbal resources were not used. Studies confirm that healthcare professionalism often underestimates the health literacy needs of adults, ${ }^{31}$ resulting in significant challenges not only in managing their own health but also those they care for, including their children. ${ }^{32}$ 


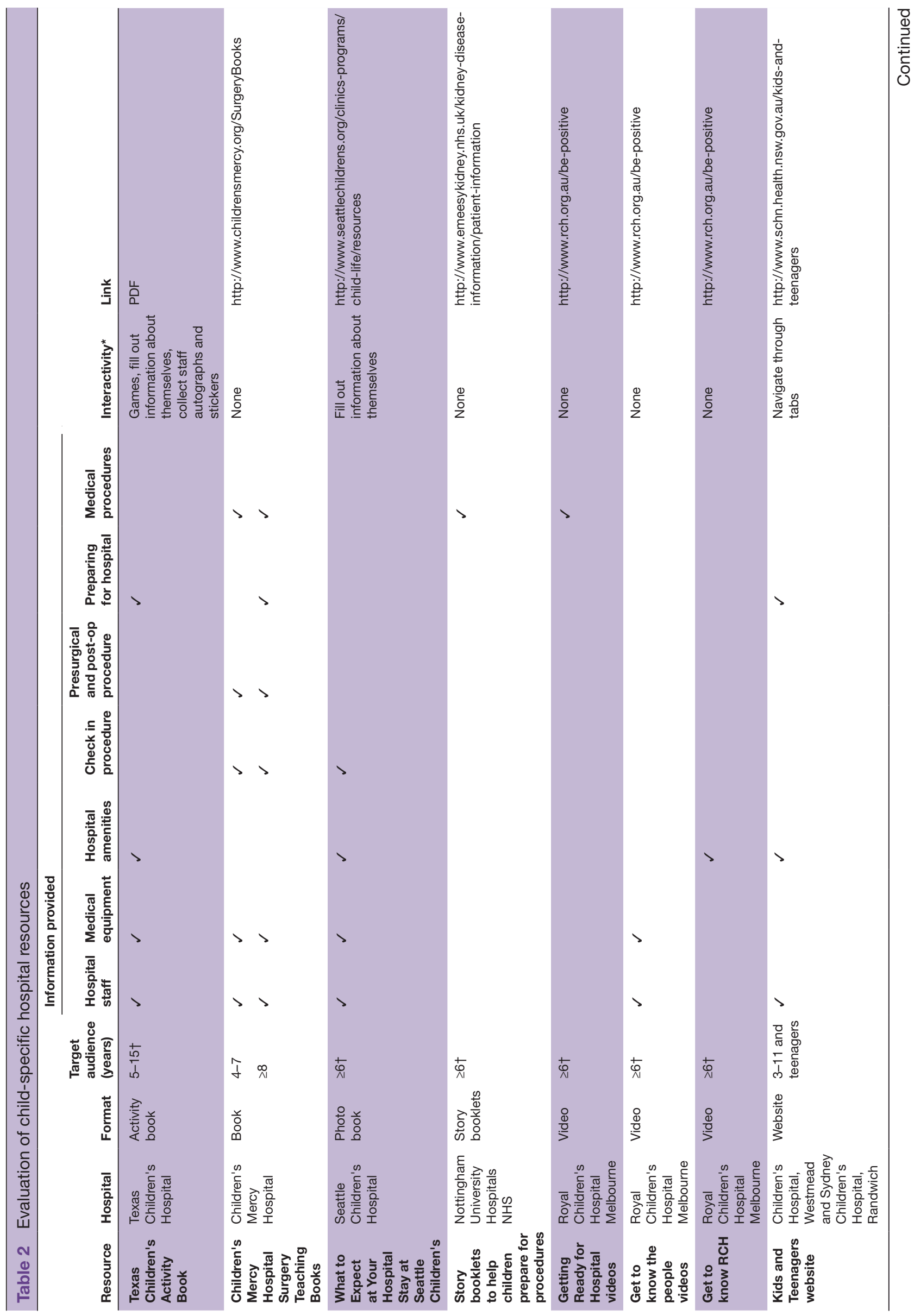

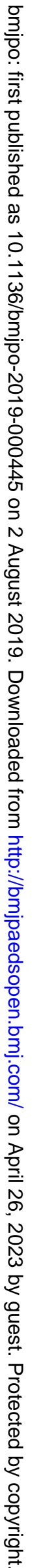




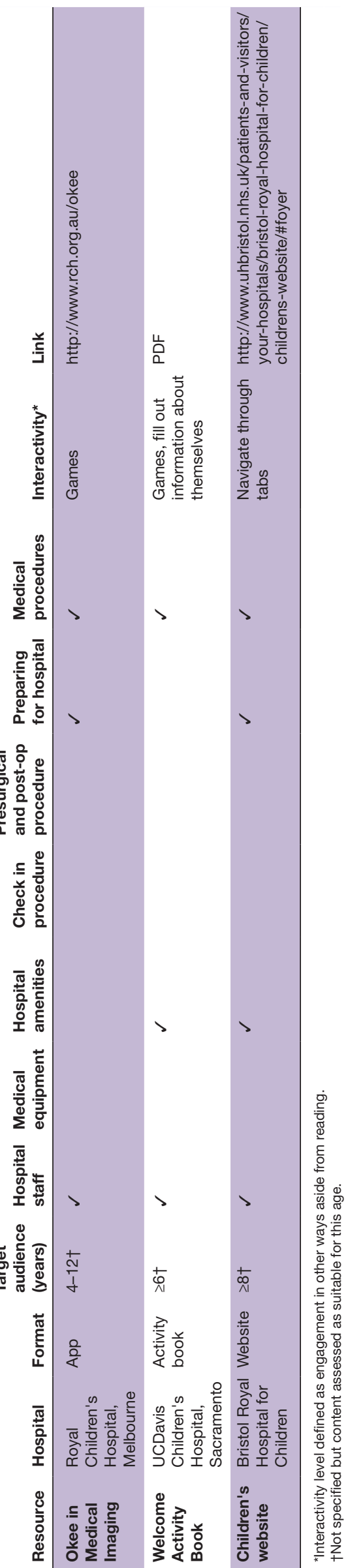

Location

UK

Non-UK

Local area

Team demographics

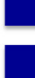

-

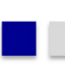

口ロ

$\square \square-\square$

$\square \square \square$

Before hospital visit

口曰

口ם

After hospital visit

口ㅁㄷㅏ.

口a

Hospital amenities

Hospital meals/ food

口ㅁㄴ

an

Children resources

Child-specific information

Family support/resources

Family accommodation

Advice for families

Departments/ services

Conditions \& treatment

Feedback

ㅁㅁ믄

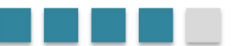

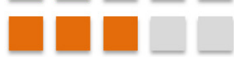

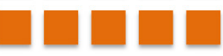

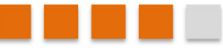

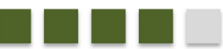

口曰ם

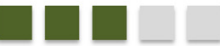

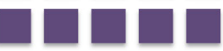

ㅁㅁ뭄

Figure 1 Evaluation of hospital websites. An average score (0-5) was calculated for each category assessed for all UK and non-UK hospitals (Australia and USA) as described in the Methods section.

There was significant agreement between information categories which parents, children and staff identified as important (figure 2), all of which were addressed in the resources reviewed. High-quality resources were predominantly from privatised healthcare settings, such as the USA. For these hospitals, the websites may be a source of marketing, promotion and income in addition to providing practical process information. Additionally, patients who pay for their care, either directly or through insurance, may have higher expectations on the quality of service information provided.

There is a need to adapt the quantity and quality of information for children and families in relation to the child's development, narrative and written competence of families,

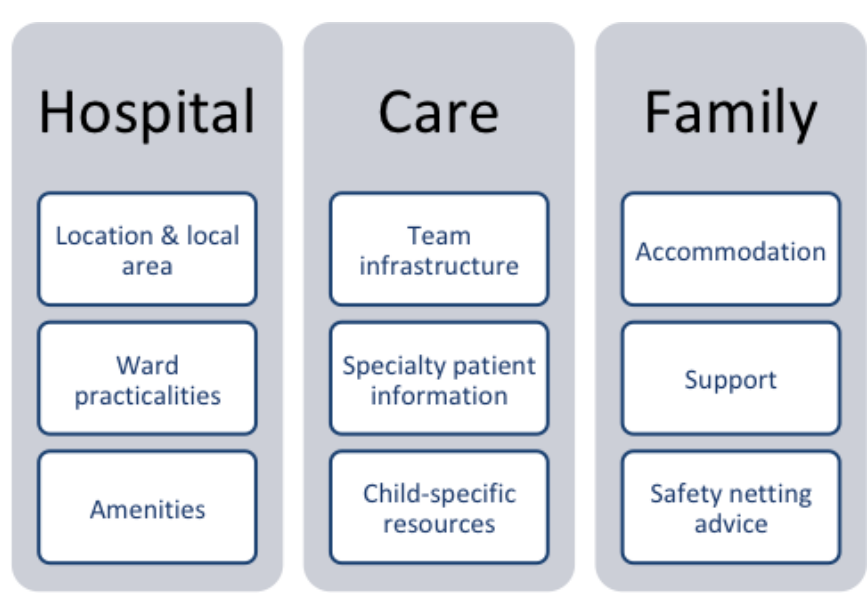

Figure 2 Resource information categories considered important by parents, children and staff. There was significant overlap between topics which parents, children and staff identified as important. 
cultural backgrounds and timing of acute admission. Our unit staffs comment that families need immediate diagnostic information at point of admission and operational information within 12-24hours; however, further study on the information needs of children and families and assumptions made about these needs during the timeline of their admission would be beneficial.

The outcomes of our study agree with previous publications, ${ }^{12} 3334$ regarding resources and information valued by children, parents and staff, confirming these needs are universal, bridging cultural and geographical divides. Resources should focus on the end user, using adaptive formats to effectively meet patient needs. ${ }^{35-38}$ Professional communities should develop greater health literacy responsive organisations ${ }^{39}$ ensuring equity of access to resources, differentiation of content according to age, narrative and written competence; adapt to any specific learning needs, thus fulfilling CRC requirements.

\section{Limitations}

Our study was limited by the small sample size; the interview setting and condition of individual children may have impacted the quality of responses. The majority of children involved were under the age of 5 , reflecting a consistent inpatient demographic; however, the needs identified may be age specific, not reflecting the needs of older children. Further detailed study involving adequate numbers in wider age groups would be required. Novel techniques such as "experience-based co-design ${ }^{40}$ could be used for older children in future studies.

It is possible that some child-specific resources may have been missed, as not all resources are accessible to the general public. Additionally, only six hospitals contacted directly responded to our query, further limiting our study. This could be improved in future studies by including additional hospitals and third sector patient information

\section{What is known about the subject?}

- A child-centred care approach should be used to ensure paediatric patients feel supported and are provided with sufficient information to engage in their healthcare.

- More work is required to involve children in paediatric healthcare as reports have highlighted that children do not feel included.

- The majority of studies focus on planned hospital admissions and minimising procedural anxiety.

\section{What this study adds?}

This study demonstrates the variation in provision of child-specific information and resources within a single institute.

- Children, parents and play specialists felt that additional child-specific information would be beneficial, in particular regarding ward practicalities, medical procedures and daily life in hospital.

- More child-specific information resources are provided in US and Australian hospitals compared with the UK; resources vary including activity and storybooks, videos and applications. sources, including hospital Facebook pages, and considering more effective methods of engaging hospitals.

\section{Outcomes and conclusion}

Paediatric patients are encouraged to engage with their healthcare decisions but cannot do so unless they are fully informed. Resources should be optimised and developed to ensure the information needs of patients are being met; this is particularly pertinent in paediatrics where such resources may act to empower and engage children in healthcare.

The study results were fed back to families and clinical management teams. Paediatric patients and family feedback then informed the design of new resources for paediatric inpatients to fill the 'information gap'. The first pilot of our new resource demonstrated active engagement and enthusiasm from the children during their admission and greater patient and family satisfaction, in comparison to those without the resource. Further PDSA cycles are underway with children of different age groups to finalise booklet details. We believe this will ensure our team meet the health needs of children and families admitted under our care.

Contributors MAP collected and analysed data, and wrote the first draft. $\mathrm{NB}, \mathrm{CH}$ $\mathrm{MK}, \mathrm{EK}$ and $\mathrm{OY}$ collected and analysed data, and contributed to the final draft. $\mathrm{HC}$ contributed to the final draft and interpretation of results. SJ conceptualised the project, contributed to the final draft and interpreted the results.

Funding The authors have not declared a specific grant for this research from any funding agency in the public, commercial or not-for-profit sectors.

Competing interests None declared.

Patient consent for publication Not required.

Ethics approval The project was registered and approved by the quality improvement team; formal ethical approval was not required as the study was an audit of current process and patient experience with no interventions undertaken.

Provenance and peer review Not commissioned; externally peer reviewed.

Data availability statement Data are available on reasonable request.

Open access This is an open access article distributed in accordance with the Creative Commons Attribution Non Commercial (CC BY-NC 4.0) license, which permits others to distribute, remix, adapt, build upon this work non-commercially, and license their derivative works on different terms, provided the original work is properly cited, appropriate credit is given, any changes made indicated, and the use is non-commercial. See: http://creativecommons.org/licenses/by-nc/4.0/.

\section{REFERENCES}

1. Department for Education. The United nations convention on the rights of the child: how legislation underpins implementation in England. London; 2010.

2. House of Lords, House of Commons, Joint Committee on Human Rights. The UK's compliance with the UN Convention on the Rights of the Child. London; 2015.

3. RCPCH. State of child health report 2017. London; 2017.

4. RCPCH. State of child health. Scotland - two years on. London; 2019.

5. RCPCH. State of child health. England - two years on. London; 2019.

6. Coyne I. Children's experiences of hospitalization. J Child Health Care 2006;10:326-36.

7. Melnyk BM, Alpert-Gillis LJ. The cope program: a strategy to improve outcomes of critically ill young children and their parents. Pediatr Nurs 1998;24:521-7.

8. Coyne I, Hallström I, Söderbäck M. Reframing the focus from a family-centred to a child-centred care approach for children's healthcare. J Child Health Care 2016;20:494-502. 
9. Council of Europe. Council of Europe recommendation on the participation of children and young people under the age of 18 Strasbourg; 2012.

10. Department of Health. Getting the right start : National Service Framework for Children; 2003. www.doh.gov.uk/nsf/children/ gettingtherightstart

11. National voices, think local act personal. my life, my support, my choice; 2015.

12. Care Quality Commission. 2016 Children and young people's inpatient and day case survey Statistical release; 2017.

13. The Patient Experience Network. Improving patient experience for children and young people; 2014.

14. Children's Parliament. Make sure we feel like we matter - a consultation report for NHS Lothian. Edinburgh; 2014.

15. Lewis I, Lenehan C, Shribman S. Report of the Children and Young People's Health Health Outcomes Forum; 2014. https://assets. publishing.service.gov.uk/government/uploads/system/uploads/ attachment data/file/410482/CYPHOF_Report 2014-15.pdf

16. Evans R. Report of survey findings: celebrating the best of children's and young people's experience of care; 2013.

17. Perry JN, Hooper VD, Masiongale J. Reduction of preoperative anxiety in pediatric surgery patients using age-appropriate teaching interventions. J Perianesth Nurs 2012;27:69-81.

18. Nilsson E, Svensson G, Frisman GH. Picture book support for preparing children ahead of and during day surgery. Nurs Child Young People 2016;28:30-5.

19. O'Conner-Von S. Preparing children for surgery--an integrative research review. Aorn J 2000;71:334-43.

20. Lerwick JL. Psychosocial implications of pediatric surgical hospitalization. Semin Pediatr Surg 2013;22:129-33.

21. DeMaso DR, Snell C. Promoting coping in children facing pediatric surgery. Semin Pediatr Surg 2013;22:134-8.

22. O'Shea M, Cummins A, Kelleher A. The perceived effectiveness of a pre-admission visit for children (and their parents) undergoing day surgery procedures. J Perioper Pract 2011;21:244-8.

23. Murphy-Taylor $\mathrm{C}$. The benefits of preparing children and parents for day surgery. Br J Nurs 1999;8:801-4.

24. Justus R, Wyles D, Wilson J, et al. Preparing children and families for surgery: Mount Sinai's multidisciplinary perspective. Pediatr Nurs 2006;32:35-43.

25. Ellerton ML, Merriam C. Preparing children and families psychologically for day surgery: an evaluation. J Adv Nurs 1994;19:1057-62

26. Li HCW, Lopez V, Lee TLI. Psychoeducational preparation of children for surgery: the importance of parental involvement. Patient Educ Couns 2007;65:34-41.
27. Visintainer MA, Wolfer JA. Psychological preparation for surgery pediatric patients: the effects on children's and parents' stress responses and adjustment. Pediatrics 1975;56:187-202.

28. Amin A, Oragui E, Khan W, et al. Psychosocial considerations of perioperative care in children, with a focus on effective management strategies. J Perioper Pract 2010;20:198-202.

29. Lerwick JL. Minimizing pediatric healthcare-induced anxiety and trauma. World J Clin Pediatr 2016;5.

30. Wahl H, Banerjee J, Manikam L, et al. Health information needs of families attending the paediatric emergency department. Arch Dis Child 2011;96:335-9.

31. Easton PM. Exploring the pathways to poor health in the "hidden population' with low literacy [PhD thesis]. University of Dundee, 2011.

32. NHS Scotland. Making it easy: a health literacy action plan for Scotland; 2014.

33. Jones CHD, Neill S, Lakhanpaul M, et al. Information needs of parents for acute childhood illness: determining 'what, how, where and when' of safety netting using a qualitative exploration with parents and clinicians. BMJ Open 2014;4:e003874.

34. McDonald H, Rushforth $\mathrm{H}$. Children's views of nursing and medical roles: implications for advanced nursing practice. Paediatr Nurs 2006;18:32-6.

35. Chase TM. Learning styles and teaching strategies: enhancing the patient education experience. SCI Nurs 2001;18:138-41.

36. Ahmed S, Steed L, Harris K, et al. Interventions to enhance the adoption of asthma self-management behaviour in the South Asian and African American population: a systematic review. NPJ Prim Care Respir Med 2018;28.

37. Clifton DC, Benjamin RW, Brown AR, et al. A tablet-based educational tool: toward more comprehensive pediatric patient education. Clin Pediatr 2018;57:1176-82.

38. Abrol E, Groszmann M, Pitman A, et al. Exploring the digital technology preferences of teenagers and young adults (TYA) with cancer and survivors: a cross-sectional service evaluation questionnaire. J Cancer Surviv 2017;11:670-82.

39. NHS Scotland. Making it easier: a health literacy action plan for Scotland; 2017.

40. Point of Care Foundation. EBCD: experience-based co-design toolkit, 2019. Available: https://www.pointofcarefoundation.org.uk/ resource/experience-based-co-design-ebcd-toolkit/?gclid=EAla IQobChMlwbHo1MLz4QIVGLLtCh2-EgeDEAAYASAAEgLNVvD_BwE [Accessed 28 Apr 2019]. 